Biomass and Bioenergy, Volume 74, March 2015, Pages 180-192

DOI:10.1016/j.biombioe.2015.01.020

\title{
A numerical model for the fractional condensation of pyrolysis vapours
}

\author{
V. S. Kiran Kumar Palla ${ }^{1,2}$, K. Papadikis ${ }^{1 *}$, S. Gu. ${ }^{3}$ \\ ${ }^{1}$ Department of Civil Engineering, Xi' an Jiaotong-Liverpool University, Suzhou, China. \\ ${ }^{2}$ School of Engineering, University of Liverpool, Liverpool, U.K. \\ ${ }^{3}$ School of Engineering, Cranfield University, Bedfordshire MK43 0AL. \\ *Corresponding author \\ E-mail address: konstantinos.papadikis@xjtlu.edu.cn
}

\begin{abstract}
Experimentation on the fast pyrolysis process has been primarily focused on the pyrolysis reactor itself, with less emphasis given to the liquid collection system (LCS). More importantly, the physics behind the vapour condensation process in LCSs has not been thoroughly researched mainly due to the complexity of the phenomena involved. The present work focusses on providing detailed information of the condensation process within the LCS, which consists of a water cooled indirect contact condenser. In an effort to understand the mass transfer phenomena within the LCS, a numerical simulation was performed using the Eulerian approach. A multiphase multi-component model, with the condensable vapours and non-condensable gases as the gaseous phase and the condensed bio-oil as the liquid phase, has been created. Species transport modelling has been used to capture the detailed physical phenomena of 11 major compounds present in the pyrolysis vapours. The development of the condensation model relies on the saturation pressures of the individual compounds based on the corresponding states correlations and assuming that the pyrolysis vapours form an ideal mixture. After the numerical analysis, results showed that different species condense at different times and at different rates. In this simulation, acidic components like acetic acid and formic acids were not condensed as it was also evident in experimental works, were the $\mathrm{pH}$ value of the condensed oil is higher than subsequent stages. In the future, the current computational model can provide significant aid in the design and optimization of different types of LCSs.
\end{abstract}

Keywords: Condensation, Liquid collection system, Species transport, Fast pyrolysis, Phase change.

\section{Introduction}

In recent years, the research on renewable energy is gaining momentum because of the shortage of fossil fuels and emission problems [1]. Among the various kinds of renewable energy sources, biomass is widely considered to be an important energy source for the future as it is the only source in this category which can produce solid, liquid and gaseous fuels [2]. Biomass can be converted to more valuable forms of energy through a number of processes including thermal, biological, and mechanical or physical processes. Even though the pyrolysis technique has been applied for thousands of years, it has gained a considerable interest only during the last 30 years [3]. Fast pyrolysis is a 
popular thermochemical conversion method, which takes place at moderate temperatures (around $500^{\circ} \mathrm{C}$ ) and very short reaction times (around $2 \mathrm{~s}$ ) [3]. The process results in high yields of liquids (bio-oil) of up to 75 wt. \% which can be used directly in a variety of applications or used as an efficient energy carrier in the upgraded form $[4,5]$.

The properties of the bio-oil fuel can be significantly improved by treatment prior to the LCS system operation (e.g catalytic pyrolysis) or post treatment (e.g hydroprocessing) after the liquid bio-oil collection. A typical issue with the hydroprocessing of bio-oils is that different components react differently in the presence of catalysts under specific conditions [6] . Moreover, the removal of sugar type of components from the pyrolysis oils prior to the hydroprocessing is highly recommended as these components are prone to coking [7]. Therefore, selective condensation which enables the fractionation of the bio-oil might be an efficient way to produce specific liquid fuels and chemicals compared to the direct complete condensation of pyrolysis vapours before upgrading $[8,9]$.

Despite the fact that several researchers have focused on the modelling of the pyrolysis reactors [10 17] cyclone separators and even ESPs (electrostatic precipitators) [18-20] used in pyrolysis technology, very few research attempts have been made on the modelling of the condensation units $[21,22]$. This is primarily due to the complex nature of the physics involved in the condensation process of pyrolysis vapours. Also, the limited availability, or in some cases the total absence, of experimental data for specific types of condensers, impose significant restrictions in the development of detailed and validated numerical models.

The development of a condensation model prerequisites a representative description of the pyrolysis vapour components. Typical bio-oil consists of a complex mixture of over 300 chemical components [23]. From the literature it is observed that few computational modelling efforts have been made on the evaporation of biomass pyrolysis oil droplets. Two approaches were primarily used to represent the bio oil composition. One approach is with a continuous thermodynamics model [24 - 27] and another with a discrete representation based on selected components in the bio-oil [28] .

In the continuous thermodynamics model, a multi-component mixture like bio-oil can be represented by few chemical groups that can be characterized using probability density functions. The parameters of each distribution function can be derived by conducting numerical distillation tests [24] . This technique has been successfully employed so far in the evaporation modelling of the bio oil. Numerous studies are based on this principle. However, this may not be true for biomass derived oil; mainly because of its nature and that it cannot be easily distillable [29] .

On the other hand, the discrete representation of the bio-oil composition facilitates the inclusion of a finite number of species which can be deduced from GC/MS analysis. Conversely, representing biooil's composition with this method is not complete, as the bio-oil is composed of hundreds of different species. Evaporation modelling of bio-oil droplets with this method was presented by Brett et al. [31] . 
Papadikis et al. [21] utilized this discrete representation of the pyrolysis vapour components to simplify the complex condensation characteristics. However, this model assumes a uniform vapour composition that remains constant throughout the condensation process. In the actual physics of the condensation of vapours, different components of the pyrolysis vapours condense at different rates and hence the composition of the vapours varies continuously.

The scope of this paper is to simulate the phase change phenomena and to capture the selective condensation of the pyrolysis vapours inside the liquid collection system (LCS). In this study a double surface water condenser shown in Fig. 1 is utilized in the LCS. The commercial CFD code ANSYS Fluent 13.0 has been used as the computational platform for the simulation of the condensation process. The phase change phenomena were incorporated to the code as user defined functions.

\section{Experimental conditions}

The double surface water condenser (Fig. 1) was used in the experiments conducted at Aston University as a first stage condenser within the liquid collection system (LCS) [32] . According to Salter [32] , the flow rate of the cooling water is $2 \mathrm{~L} / \mathrm{min}$ at $15^{\circ} \mathrm{C}$ and the vapour flow rate into the condenser $12 \mathrm{~L} / \mathrm{min}$ at $500^{\circ} \mathrm{C}$. The vapour flow includes condensable and non-condensable gases. In the current computational model the wall surfaces, which are exposed to the water, are modelled with constant temperature of $15^{\circ} \mathrm{C}$ with an assumption of marginal increase in cooling water temperature in the system.

Biomass was injected to the experimental reactor at a rate of $100 \mathrm{~g} / \mathrm{hr}$. According to the mass balances obtained from the experiments, the total conversion of biomass into vapours is approximately 70 wt.\%, whereas the non-condensable gases amount to $15 \mathrm{wt} . \%$ and char yielded from $9-11 \%$. A mass imbalance of $5 \%$ was reported for a pyrolysis reactor temperature of $500^{\circ} \mathrm{C}$. It is worth to note that the previously mentioned yields are sensitive to the pyrolysis reactor temperature [33]. In the above experiments Nitrogen has been used as the carrier gas, which is also modelled together with the noncondensable gases.

\section{Condensation model}

The condensation model used in this paper is an analytical improvement of the Papadikis et al. [21] condensation model. In contrast with the uniform vapour composition presented in the model of Papadikis et al. [21] , the current model treats each individual species as a separate compound that is condensed according to its individual saturation vapour pressure. In this way, fractional condensation modelling is enabled and the prediction of the bio-oil composition at each condensation stage becomes possible, once the initial vapour composition is known. The pyrolysis vapour composition is 
highly dependent on the type of feed used during the pyrolysis process. This composition further prescribes the type of application for which the produced bio-oil will be used for [30] . The pyrolysis vapours are modelled by using a discrete representation of 11 chemical species dominant in bio-oil. The chemical species listed in Table 1, have been taken from the bio-oil composition used in the Brett et al.'s [31] work. This composition represents a discrete equivalent of the continuous thermodynamics model, which in turn is based on molecular weight distributions of specific chemical groups, used in the study of Hallet and Clark [27]. It has to be noted that the selection of the number of chemical species and their corresponding initial volume fractions can be modified depending on the chemical compounds of interest. However, one has to make sure that the overall average distribution of the affected chemical groups in the continuous description remains unchanged. This inevitably imposes a limitation on the minimum number of discrete chemical compounds in group, which will have to satisfactorily approximate a continuous curve. The thermochemical properties of each species were computed based on existing data available in the literature [34]. The critical properties are computed by using the group contribution method [35] when they are not readily available in the literature. These properties of the individual species were listed in the Table 1.

The present model estimates the saturation vapour pressure of the each species present in the pyrolysis vapours by utilising the generalized corresponding states method. According to Mejbri and Bellagi's [36] generalized three parameter corresponding states correlation, the natural logarithm of the reduced saturated vapour pressure and acentric factor $\omega^{i}$ are in linear relation as shown in eq. 1 with an averaged fluctuation about $0.16 \%$.

$$
\ln \left(P_{r}^{i}\right)=f_{0}\left(\tau^{i}\right)+\omega^{i} f_{1}\left(\tau^{i}\right)
$$

where $\tau^{i}$ is the inverse of the reduced temperature $T_{r}^{i}$ of the $i^{\text {th }}$ species and is equal to $1 / T_{r}^{i}$. The functions $f_{0}$ and $f_{1}$ are given by eqs. 2 and 3 .

$$
f_{0}\left(\tau^{i}\right)=\gamma_{1}\left(\tau^{i}-\exp \left(1-\tau^{i}\right)\right)+\gamma_{2}\left(\left(\tau^{i}\right)^{\gamma_{3}}-\exp \left(1-\tau^{i}\right)\right)
$$

and

$$
f_{1}\left(\tau^{i}\right)=\gamma_{4}\left(\tau^{i}-\exp \left(1-\tau^{i}\right)\right)+\gamma_{5}\left(\left(\tau^{i}\right)^{\gamma_{6}}-\exp \left(1-\tau^{i}\right)\right)
$$

The values of the six universal $\gamma$ coefficients which were used in above two equations are listed in Table 2.

For estimating vapour pressures by using eq. 1, the critical pressures and temperatures are needed along with the acentric factor. If the acentric factor is not available, Mejbri and Bellagi [36] recommended estimating it using the boiling temperature $T_{b}^{i}$ by using following equation

$$
\omega^{i}=\left(0.013162987-\ln P_{c}^{i}-f_{0}\left(\tau_{b}^{i}\right)\right) / f_{1}\left(\tau_{b}^{i}\right)
$$


where $\tau_{b}^{i}$ is the ratio between critical and boiling temperatures i.e. $\tau_{b}^{i}=T_{c}^{i} / T_{b}^{i}$. The critical pressure $P_{c}^{i}$ used in eq. 4 is expressed in bars.

The condensation rate is governed by the magnitude of the relative saturation value which is the ratio of the vapour fugacity $\left(f_{v}^{i}\right)$ to the saturated vapour fugacity $\left(f_{l}^{i}\right)$. Under the vapour liquid equilibrium (VLE) conditions, the relative saturation will be unity. The vapour fugacity in this case is the partial pressure of the particular species in the system as given in the eq. 5 .

$$
f_{v}^{i}=\phi^{i} P^{i}=\phi^{i} y^{i} P
$$

where $P^{i}$ is the partial pressure of the species ' $\mathrm{i}$ ' and $P$ is the total pressure of the mixture. $y^{i}$ is the mass fraction of the ith species within the vapour mixture.

The saturated vapour fugacity can be computed from the reduced saturation pressure as shown in eq. 6.

$$
f_{l}^{i}=\phi_{s a t}^{i} P_{r}^{i} P_{c}^{i}
$$

Here the fugacity coefficients $\phi^{i}$ and $\phi_{\text {sat }}^{i}$ are assumed as 1 and hence the saturated vapour pressure considered same as saturated vapour fugacity. This is especially true when the system is not under high pressures.

\section{Thermodynamic properties}

The thermodynamic properties of the vapour mixture are calculated based on the assumption that the vapour behaves as an ideal mixture. The viscosity of the vapour mixture is estimated based on the Dean and Stiel [37] relation which is a function of the reduced mixture temperature. Mixture viscosity $\mu_{m}$ in eq. 7 is expressed in micro poise.

$$
\mu_{m}=\left\{\begin{array}{ll}
3.4 T_{r m}^{8 / 9} / \xi_{m} & T_{r m} \leq 1.5 \\
16.68\left(0.1338 T_{r m}-0.0932\right)^{5 / 9} / \xi_{m} & T_{r m}>1.5
\end{array},\right.
$$

where $\xi_{m}$ is inverse viscosity and expressed in $\mu P^{-1}$ this can be calculated by using eq. 8 .

$$
\xi_{m}=\left(\frac{T_{c m}}{\left(M_{m}{ }^{3} P_{c m}{ }^{4}\right)}\right)^{1 / 6} .
$$

The reduced mixture temperature $T_{r m}$ is expressed as the ratio between temperature and mixture critical temperature. Here the mixture critical temperatures and mixture molecular weight were calculated by mass fraction average basis i.e. $\sum y^{i} T_{c}^{i}, \sum y^{i} M^{i}$ respectively. The mixture critical pressure $P_{c m}$ expressed in terms of atm is calculated using eq. 9

$$
P_{c m}=\frac{R\left(\sum_{i} y^{i} z_{c}^{i}\right)}{\sum_{i} y^{i} V_{c}^{i}} T_{c m}
$$

In the above equation, the universal gas constant $\mathrm{R}$ is equal to 82.05746 (atm. cm3/ mol-K). 
Due to lack of the group contribution data, in this analysis, the more accurate correlations like Chung et al. [38] are not considered for calculating the thermal conductivity. The Eucken correlation offers a simple method to estimate the mixture's thermal conductivity,

$$
k_{m}=\left(1.32+\frac{1.77}{\left(C_{p_{m}} / R-1\right)}\right)\left(\frac{\mu_{m}\left(C_{p_{m}}-R\right)}{M_{m}}\right),
$$

where $k_{m}$ is the thermal conductivity of the vapours, $C_{p_{m}}$ is the heat capacity of the vapours, which is calculated on a mass fraction average, i.e. $\sum w^{i} C_{p}{ }^{i}$. Individual species heat capacities are given in Table 3. These values are obtained from Reid et al. [39] and Stull et al. [40] .

The heat of vaporization for the each chemical species within the vapour is estimated based on the law of corresponding states. The relationship of the heat of vaporisation with acentric factor, $\omega^{i}$, and the reduced temperature, $T_{r}^{i}$, is shown in eq. 11 is an analytical representation of the Pitzer's [41] correlation.

$$
\Delta H_{v}^{i}=\left(7.08\left(1-T_{r}^{i}\right)^{0.354}+10.95 \omega^{i}\left(1-T_{r}^{i}\right)^{0.456}\right) R T_{c}^{i} .
$$

In this work, the bio-oil is treated as a homogeneous compound and hence its composition is not varied spatially or temporally. Representative bio-oil properties were sourced from the works of Oasmaa and Peacocke [42, 43]. The bio-oil properties are shown in Table 4.

It has to be noted that the pyrolysis vapour and liquid bio-oil properties are subjected to errors associated with the estimation techniques and experimental values used for their computation. However, there is great confidence that the deviations from reality will not significantly affect the final results of the numerical model as the previously mentioned correlations and experimental values have been widely used and accepted by the chemical industry for several years.

\section{Fluid dynamics model}

The fluid dynamics modelling approach is based on the Eulerian multiphase model to solve two phases namely gaseous pyrolysis vapours phase and condensed bio-oil liquid phase. In order to capture the detailed chemical composition variance within the vapours across the system, the species transport model was enabled in the vapour phase, while the composition of the liquid bio-oil is considered constant. To simulate the pyrolysis vapour condensation process within the condenser, the commercial CFD package ANSYS Fluent 13 has been utilised as the computational platform. The governing equations are as follows:

Continuity equation for phase $p$

$$
\frac{1}{\rho_{r p}}\left(\frac{\partial}{\partial t}\left(a_{p} \rho_{p}\right)+\nabla \bullet\left(a_{p} \rho_{p} v_{p}\right)=\dot{m}_{q p}-\dot{m}_{p q}\right) \text {. }
$$


The term $\rho_{r p}$ is the volume averaged density of the $p^{\text {th }}$ phase. In the above equation, the mass source terms $\dot{m}_{p q} \& \dot{m}_{q p}$ corresponds to mass transfer from phase $p$ to phase $q$ and vice versa. The mass transfer from vapour phase to the bio-oil phase corresponds to the sum of the individual species mass transferred to the bio-oil. This is calculated based on the vapour liquid equilibrium (VLE) condition as mentioned in section 3 .

Momentum equation for phase $p$

$$
\frac{\partial}{\partial t}\left(a_{p} \rho_{p} v_{p}\right)+\nabla \bullet\left(a_{p} \rho_{p} v_{p} v_{p}\right)=-a_{p} \nabla P+\nabla \bullet \overline{\bar{\tau}}_{p}+a_{p} \rho_{p} \bar{g}+\bar{R}+\bar{M}_{s, p} .
$$

In the above equation, stress-stain tensor is represented by $\overline{\bar{\tau}}_{p}$ and $\bar{R}$ is the interaction force between the two phases calculated by

$$
\bar{R}=K_{p q}\left(\bar{v}_{q}-\bar{v}_{p}\right)
$$

The interphase momentum exchange coefficient $K_{p q}$ defined as

$$
K_{p q}=\frac{a_{p} a_{q} \rho_{p q} f}{\tau_{p q}}
$$

In this study, the drag function $f$ used is based on Schiller-Naumann drag model [44] and is defined as $C_{D} R e / 24$. The drag coefficient $C_{D}$ is given by eq. 16 and the relative Reynolds number $\operatorname{Re}$ is given in eq. 17.

$$
\begin{aligned}
C_{D} & = \begin{cases}24\left(1+0.15 R e^{0.687}\right) / R e & R e \leq 1000 \\
0.44 & R e>1000\end{cases} \\
R e & =\frac{\rho_{p q}\left|\bar{v}_{p}-\bar{v}_{q}\right| d}{\mu_{p q}}
\end{aligned}
$$

The particulate residence time $\tau_{p q}$ used in eq. 15 , is defined as

$$
\tau_{p q}=\frac{\rho_{p q} d^{2}}{18 \mu_{p q}}
$$

The momentum source $\bar{M}_{s, p}$ is calculated based on the mass exchanged between the phases i.e. from vapour phase to bio oil phase as shown in eq. 19

$$
\bar{M}_{s, p}=\dot{m}_{q p}\left(\bar{v}_{q}-\bar{v}_{p}\right) .
$$

Here $\dot{m}_{p q}$ is equal to the sum of all individual species mass sources condensed to form the bio-oil and is computed as $\dot{m}_{p q}=\sum_{i} \dot{m}_{c}^{i}$.

In order to solve the conservation equations for individual chemical species within the vapour phase, convection-diffusion equation of the $\mathrm{i}^{\text {th }}$ species as shown in eq. 20 is used.

$$
\frac{\partial}{\partial t}\left(\rho w^{i}\right)+\nabla \cdot \rho \bar{v} w^{i}=-\nabla \cdot \bar{J}^{i}+S^{i} .
$$

The diffusion flux $\bar{J}^{i}$ of the component $\mathrm{i}$ is computed based on Fick's law which states that mass diffusion is due to concentration gradients.

The energy conservation for phase $p$ is given as 


$$
\frac{\partial}{\partial t}\left(a_{p} \rho_{p} h_{p}\right)+\nabla \cdot\left(a_{p} \rho_{p} \bar{v}_{p} h_{p}\right)=-a_{p} \frac{\partial P_{p}}{\partial t}+\overline{\bar{\tau}}_{p}: \nabla \bar{v}_{p}-\nabla \cdot \bar{q}_{p}+Q+H_{s, p} .
$$

In eq. $21, q_{p}$ is the heat flux and $Q$ is the volumetric rate of energy transfer between two phases defined by

$$
Q=h_{p q}\left(T_{q}-T_{p}\right) .
$$

The heat transfer coefficient $h_{p q}$ between two phases was estimated based on the Ranz-Marshall correlation [45] . The heat source due to phase change $H_{s, p}$ mentioned in eq. 21 is computed by

$$
H_{s, p}=\left\{\begin{array}{lr}
\sum_{i}\left(-m_{c}^{i} H_{p}^{i}\right) & \text { for vapour phase } \\
\sum_{i} \dot{m}_{c}^{i}\left(H_{p}^{i}-\Delta H_{v}^{i}\right) & \text { for bio-oil phase }
\end{array}\right.
$$

The terms $H_{p}^{i} \& \Delta H_{v}^{i}$ are the enthalpy and latent heat of vaporisation of the speciesi. The standard k- $\varepsilon$ turbulence model was utilised to capture the turbulence effects within the system.

\section{Assumptions}

The implementation of the hydrodynamic model is based on the following assumptions.

I. The pyrolysis vapours together with the carrier gas nitrogen is treated as an ideal mixture. This is mainly due to the unavailability of the excess function data in the literature.

II. The density of the species over the computational domain was calculated based on the ideal gas assumption. However, while estimating the vapour pressures, and critical properties such as viscosity and thermal conductivity, real gas behaviour was considered.

III. The pyrolysis vapours are modelled with 11 chemical species and is assumed to represent the majority of its behaviour in terms of critical properties. This is a compromise between accuracy and the speed of the solution. In reality, pyrolysis vapours consist of more than 100 chemical compounds something that dramatically increases the computational expense of the model. However, the model presented in the present paper can be readily scalable to different species groups based on the feedstock used for pyrolysis.

IV. Fugacity coefficients are assumed as 1 . This assumption can be justified when the system is not under high pressures.

V. The non-condensable gases obtained from the mass balance done during the experiment are modelled as Nitrogen and clubbed with the carrier gas composition. The very low concentration of the non-condensable gas fraction produced during biomass pyrolysis, is not expected to significantly influence the thermodynamic and fluid dynamic behaviour of the system. 


\section{Results \& Discussions}

The geometry of the condenser used in the current CFD model is the same as the double surface condenser used in the pyrolysis experiments [31] .

Fig. 2(b) shows the volume fraction of the bio oil at the outer tube and inner tube surfaces of the condenser. The contours of the bio-oil volume fractions on the vertical section of the condenser are presented in Fig. 2(a). From this figure, it is evident that the condensation is more intense at the surfaces at which the cooling water is in contact with. It also demonstrates the bio-oil droplet accumulation on the condenser during the condensation process. The dynamics of the bio-oil mist is highly influenced by the gas flow within the condenser. This is evident from the contours on the inner tube surface volume fraction as they can be seen in Fig. 2(b), where a ripple like formation is observed. In the case of the outer tube, the gas flow at the bottom side forces the bio-oil droplets into the central zone of the annular section.

In Fig. 3, the contours of the gas temperature are shown, where it can be observed that the gas temperature is lower at the wall surfaces than in the middle zone of the annulus space between the inner and the outer tubes. The liquid bio-oil droplet formation discussed in the previous section is mainly due to this particular temperature profile of the gas. To have a clearer picture of the temperature variation along the length of the condenser, the average temperature, from the inlet to the outlet, is plotted in the same figure. The rapid vapour temperature drop can be seen in the same plot, where the inlet vapour temperature is approximately $500^{\circ} \mathrm{C}$ and the outlet temperature approximately $18^{\mathrm{O}} \mathrm{C}$. It can be observed that the most significant region for vapour cooling is located between $\approx 0.02$ $-0.07 \mathrm{~m}$ of the length of the condenser.

Fig. 4 shows the variation of the relative saturation of the different compounds along the length of the condenser. The dashed lines represent the maximum and minimum values at the different sections, while the continuous line represents the volume averaged compound saturation at each particular section of the condenser.

A compound will change phase (condense) when its relative saturation exceeds unity. From Fig. 4, it can be seen that the maximum relative saturation for Butyric Acid, Coniferyl Alcohol, Guaiacol, Phenol and water reaches its maximum value before $0.1 \mathrm{~m}$ of length, while the curve relaxes towards its equilibrium value as the vapours continue to condense beyond this region. The maximum relative saturation occurs close to the wall boundaries due to the significantly lower temperatures at those points. The minimum relative saturation values are mainly located towards the centre of the annular section where temperatures are higher. The volume averaged relative saturation line represents the volume weighted average of the relative saturation at different sections of the condenser. It shows that the average relative saturation along the condenser has an increasing trend (approaching unity) due to the rapid cooling of the vapours and gives a very good indication of the bio-oil composition at the first 
stage of condensation. One can see that for the components that the average saturation has exceeded unity, a significant proportion of them will be collected in the form of liquid bio-oil at the first stage. For some of the components with low initial partial pressures, as shown in Fig. 5 (e.g. propionic acid), only small traces will be collected that are mainly determined by the maximum relative saturation. For those components that none of the maximum and consequently none of the average and minimum saturations have exceeded unity, no traces will be detected in the final bio-oil product.

The relative mass fraction contours of each compound are shown in Fig. 6. These contours are plotted at the vertical mid-section of the condenser. At the inlet, all the values are equal to unity. As the vapours flow through the condenser, the values of the relative mass fraction decrease or increase depending on whether the compound within the condenser changes its phase to liquid bio-oil or not. Those compounds with maximum relative saturation above unity within $0.1 \mathrm{~m}$ of length keep condensing as the vapours flow along the length of the condenser. The relative mass fractions of those decrease continuously. The blue colour at the outlet indicates that a particular compound is completely condensed. Light green colour indicates that those components have been partially condensed within the condenser, whereas the red colour indicates that those compounds have been slightly or not been condensed at all.

Another interesting point that can be observed in Fig. 4 is that the values of the relative saturation increase sharply for many components at around $0.18 \mathrm{~m}$. This is primarily attributed to the rise in gas pressure near the exit of the condenser due to the diffuser effect at the point where the inner tube ends. As the inner tube ends, the cross sectional area increases steadily over a small distance which effectively gives a small rise in pressure. The maximum velocity of the vapour and the average pressure within the condenser are plotted in Figs 7 and 8 respectively. From Fig. 8, it is evident that at lower temperatures, a small increase in pressure highly increases the value of the relative saturation of the components. The relative saturation values shown in Fig. 4 indicate that at higher temperatures condensation is primarily affected by heat transfer rates whereas at later stages, where the temperature is low, they highly depend on pressure changes.

Fig. 9 shows the plot of cumulative mass source ratio along the direction of the flow. This is the ratio between the cumulative mass source of the particular component and its mass fraction at the inlet. When the value of this ratio approaches unity, it indicates the complete conversion of that particular component. From Fig. 9 we can see that Guaiacol is the first component condensed completely followed by Coniferyl Alcohol and Phenol. It is also worth noticing that Butyric Acid and water have been partially condensed within the condenser. Approximately $35 \%$ of water vapour is condensed in the bio-oil. Small traces of condensation can be seen at the end of the tube for the propionic acid. Fig. 10 shows the total mass source plot within each segment of the condenser along its length from the inlet to the outlet. The condenser has been divided into 100 equal segments along its axis and the total mass fraction shown in Fig. 10 is summed in all the cells within the individual segments. As expected, 
mainly due to the high initial concentration, the mass fraction source of Coniferyl Alcohol is the greatest among all components, followed by Guaiacol. From Fig. 10 we can see that the condensation of Guaiacol, Coniferyl Alcohol and Phenol starts at almost the same location in the condenser (approximately $0.025 \mathrm{~m}$ from the inlet). The condensation of components like water and Butyric acid starts at approximately $0.05 \mathrm{~m}$ from the inlet. In the case of water, a considerable amount is transferred from the vapour phase to liquid bio-oil phase near the outlet region. This is mainly due to increased pressure at lower temperatures. From Fig. 10 we can safely conclude that most of the condensation takes place between 0.025 to $0.1 \mathrm{~m}$ of the condenser.

The reduced temperature variation of all components within the vapour phase can be seen in Fig. 11 . The reduced temperature, which represents the ratio between the vapour temperature and the corresponding component's critical temperature, varies between 1.5 and 0.4. More importantly between the lengths $0.025 \mathrm{~m}$ and $0.1 \mathrm{~m}$ where maximum condensation taking place, the reduced temperatures vary between 1.0 and 0.6. This is an essential condition for using the enthalpy of condensation relationship mentioned in eq. 11. The enthalpy of condensation for each condensed components is plotted separately in Fig. 12. The continuous line represents the total enthalpy of vaporisation within each axial segment of the condenser. The plot follows a similar trend as mass sources plot shown in Fig. 10. The enthalpy of vaporization values are embedded into the solver as energy source terms and are removed from the bio-oil phase. Dotted lines represent the maximum value of the enthalpy of condensation within a particular segment. The maximum enthalpy of condensation both in terms of total and maximum value is observed for Coniferyl Alcohol and followed by Guaiacol. One order of magnitude lower values are observed in the case of water and Phenol in comparison to Coniferyl alcohol. The rest of the acids contributed relatively negligible amounts of enthalpy towards the outlet region of the condenser.

The gas velocity vectors inside the condenser can be seen in Fig. 13. Velocity varies from $3.5 \mathrm{~m} / \mathrm{s}$ at the entrance to $1.5 \mathrm{~m} / \mathrm{s}$ at the exit. The maximum velocity throughout the length of the condenser is approximately $1 \mathrm{~m} / \mathrm{s}$. From the vector plot in Fig. 13, we can see that some small recirculation zones are formed near the entrance. Near the outlet we can see a small drop in the velocity followed by a sharp increase in it; this is also evident in Fig. 7. This phenomenon can be attributed to the sudden expansion of the cross-sectional area at the end of the inlet tube, which at the same time induces some gas recirculation at that region, followed by another contraction at the very end of the condenser. Overall, the vapour residence time is well below $1 \mathrm{~s}$. This implies that a rapid condensation taking place within the condenser, thus greatly minimising the possibility of secondary vapour cracking in the condenser.

From the experiments it has been observed that the exit temperature is around $23^{\circ} \mathrm{C}$ whereas in the numerical simulation an average outlet temperature of approximately $18^{\circ} \mathrm{C}$ is predicted. The numerical simulations slightly over predict the heat transfer as the Ranz-Marshal correlation assumes 
that the secondary phase forms spherical droplets in the primary one. Moreover, the temperature at the outlet varies spatially over the entire section so it was not clear at what location the actual measurement has been taken. Fivga's [46] experiments, in which the same equipment has been used, also showed that the water vapour partially condensed in this stage of the liquid collection system. In the experiments, the condensed water percentage varies between 30 to $45 \%$ of the total water content. It is also mentioned that the $\mathrm{pH}$ value of the first stage condensed bio-oil is higher than the subsequent collection stages. This was primarily due to the condensation of the acidic components at the later stages. In this numerical study, we also observed the similar trend where acids like formic acid and acetic acid are not condensed in the present condenser.

It is worth commenting that the vapour thermochemical properties and in turn the condensation patterns of it will vary if a different initial vapour composition is used. In the real cases, the bio-oil and pyrolysis vapour composition is much more complex than the one described in this work. However, the numerical predictions of the present simulation showed a very good agreement with the experimental results. Based on the type of biomass and the type of compounds present in it, the composition can be modified or further simplified. This can be precisely done by considering the specific components of interest, whereas the thermodynamic properties of the composition can be estimated accordingly. In this way, this condensation model can be utilised during the designing stage of biomass specific or function specific heat exchangers/condensers.

It has to be noted that the obtained results from this work are specific to the indirect contact heat exchanger under study and cannot be directly extrapolated to other types of condensers. Each type of condenser possesses its own heat transfer and fluid dynamic characteristics which will in turn affect the equilibrium properties of the vapour compounds. In addition to that, scaling up of the equipment will also have a similar impact since the thermal and flow field inside the condensing equipment will be affected by the size alteration. However, the methodology presented in this model can be directly utilised for the design and optimisation of different types and sizes of condensers used in the bio-oil liquid collection systems.

\section{Conclusions}

A species transport model has been implemented within the Eulerian multiphase approach to model the fractional condensation of bio-oil. The generalised corresponding states method has been used to estimate the saturation vapour pressure of the individual components. In this study, 11 discrete chemical compounds were selected to represent the pyrolysis vapours composition, together with Nitrogen which represents the carrier gas and the non-condensable fraction. The mixture of pyrolysis vapours was treated as an ideal gas mixture. From the simulations, it was observed that only few components condensed completely in this stage of the condenser something that it is in good agreement with the experimental observations. According to Fivga's [46] experimental study, only $30 \%$ 
of the water vapour was condensed. Guaiacol, Coniferyl Alcohol and Phenol components were completely condensed within the first half of the length of the condenser, whereas no traces of formic and acetic acid condensation were detected. It is also observed that the marginal increase in the pressure at the lower temperature towards the outlet of the condenser resulted in the increase of the relative saturation of water and other acidic components. The reduced temperatures within the condensing region for most of the components fall in the range of 1 to 0.5 , which is the recommended range for using the Pitzer correlation for estimating the enthalpy of condensation.

\section{Acknowledgement}

The authors gratefully acknowledge the financial support for this work by the UK Engineering and Physical Sciences Research Council (EPSRC) project grant: EP/K036548/1 and the EU FP7 IPACTS (268696) and iComFluid Projects (312261). 


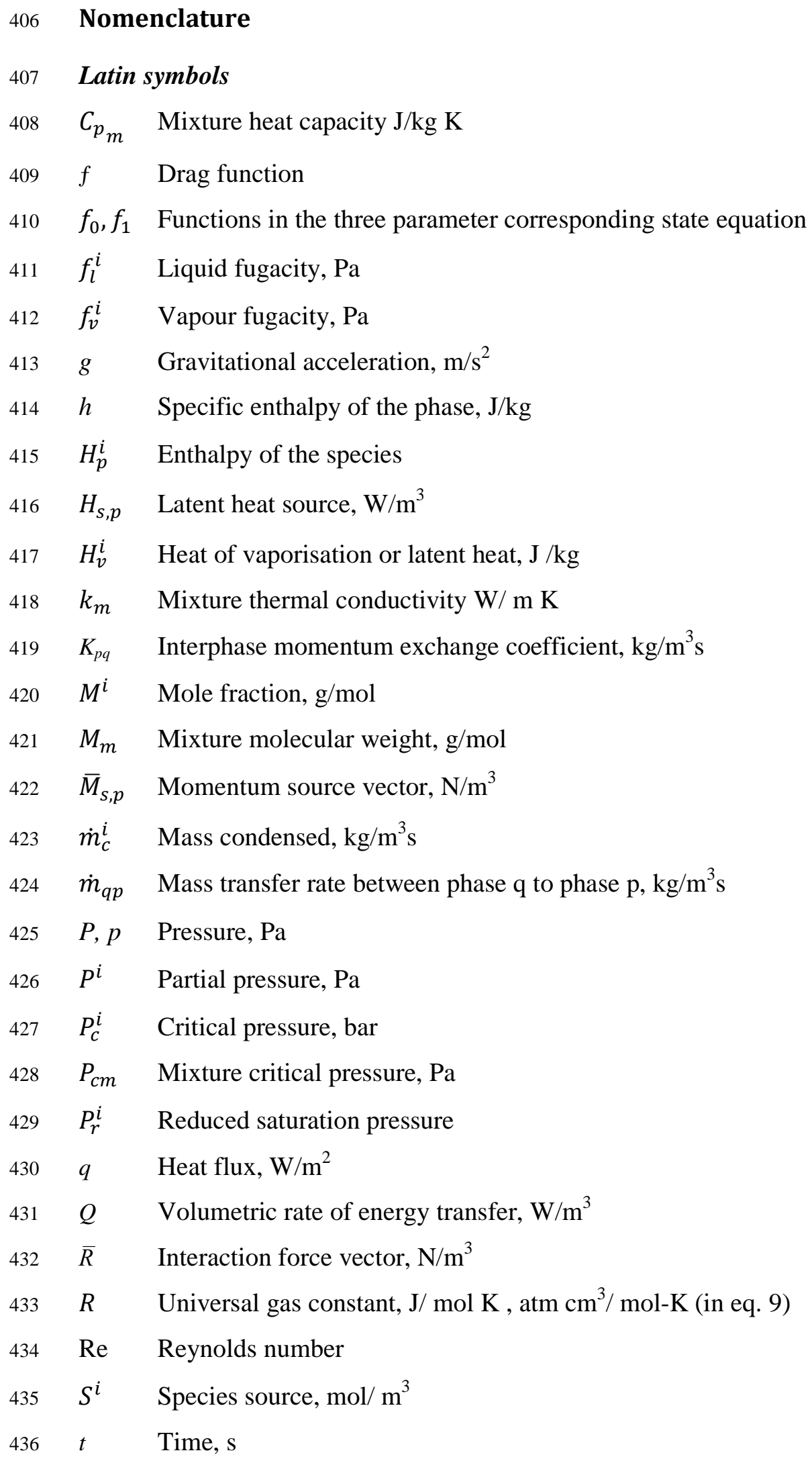




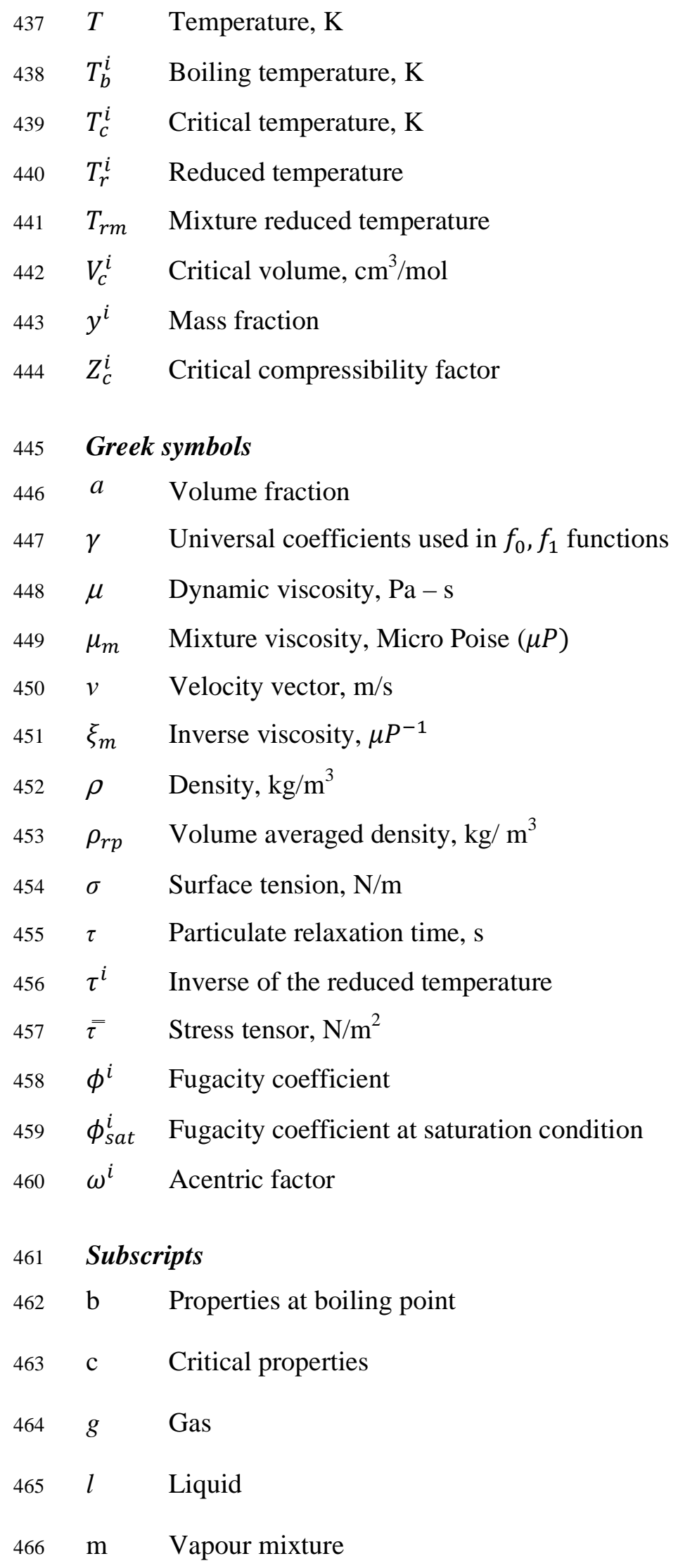


$467 \quad p, q \quad$ Phase index

$468 \quad p q \quad$ Volume averaged properties

$469 \quad \mathrm{r} \quad$ Reduced properties

$470 \quad$ S $\quad$ Source term

471 sat Values at saturation point

$472 v \quad$ Vapour

473 Superscripts

$474 \quad i \quad$ species index in the vapour mixture 


\section{References}

[1] Renzhan Y, Ronghou L, Yuanfei M, Wenting F, Xingquan S. Characterization of biooil and bio-char obtained from sweet sorghum bagasse fast pyrolysis with fractional condensers. Fuel 2013; 112: 96-104.

[2] Bridgwater AV, Peacock GVC, Fast pyrolysis processes for biomass. Renew Sust Energ Rev 2000; 4: 1-74.

[3] Bridgwater AV. Review of fast pyrolysis of biomass and product upgrading. Biomass Bioenerg 2012; 38: 68-94.

[4] Czernik S, Bridgwater AV. Overview of application of biomass fast pyrolysis oil. Energ Fuel 2004; 18: 590-598.

[5] Agblevor FA, Mante O, McClung R, Oyama ST. Co-processing of standard gas oil and bio crude oil to hydrocarbon fuels. Biomass Bioenerg 2012; 45: 130-137.

[6] Elliott DC. Historical Developments in Hydroprocessing Bio-oils. Energ Fuels 2007; 21: 1792-1815

[7] Lindfors C, Kuoppala E, Oasmaa A, Solantausta Y, Arpiainen V. Fractionation of BioOil. Energ Fuels 2014; 28: 5785-5791.

[8] de Miguel Mercader F, Groeneveld MJ, Kersten SRA, Geantet C, Toussaint G, Way NWJ, Schaverien CJ, Hogendoorn JA. Hydrodeoxygenation of pyrolysis oil fractions: process understanding and quality assessment through co-processing in refinery units. Energy Environ Sci 2011; 4: 985-997.

[9] Butler E, Devlin G, Meier D, McDonnell K. A review of recent laboratory research and commercial developments in fast pyrolysis and upgrading. Renew Sust Energy Rev 2011; 15: 4171-4186.

[10] Di Blasi C. Modelling the fast pyrolysis of cellulosic particles in fluid-bed reactors. Chem Eng Sci 2000; 55: 5999-6013.

[11] Babu BV, Chaurasia AS. Pyrolysis of biomass: improved models for simultaneous kinetics and transport of heat, mass, and momentum. Energ Convers Manage 2004; 45: $1297-1327$.

[12] Liang XH, Kozinski JA. Numerical modeling of combustion and pyrolysis of cellulosic biomass in thermo gravimetric systems. Fuel 2000; 79(12): 1477-1486. 
[13] Papadikis K, Gu S, Bridgwater AV. Geometrical Optimization of a Fast Pyrolysis Bubbling Fluidized Bed Reactor Using Computational Fluid Dynamics. Energ Fuel 2010; 24: 5634-5651.

[14] Papadikis K, Bridgwater AV, Gu S. CFD modelling of the fast pyrolysis of biomass in fluidised bed reactors, Part A: Eulerian computation of momentum transport in bubbling fluidised beds. Chem Eng Sci 2008; 63(16): 4218-4227.

[15] Papadikis K, Gu S, Bridgwater AV. CFD modelling of the fast pyrolysis of biomass in fluidised bed reactors. Part B: heat, momentum and mass transport in bubbling fluidised beds. Chem Eng Sci 2009; 64(5): 1036-1045.

[16] Papadikis K, Gerhauser H, Bridgwater AV, Gu S. CFD modelling of the fast pyrolysis of an in-flight cellulosic particle subjected to convective heat transfer. Biomass Bioenerg 2009; 33(1): 97-107.

[17] Papadikis K, Gu S, Bridgwater AV, Gerhauser H. Application of CFD to model fast pyrolysis of biomass. Fuel Process Technol 2009; 90(4): 504-512.

[18] Azadi M, Mohebbi A. A CFD study of the effect of cyclone size on its performance parameters. J Hazard Mater 2010; 182(1-3): 835-841.

[19] Raoufi A, Shams M, Kanani H. CFD analysis of flow field in square cyclones. Powder Technol 2009; 191(3): 349-357.

[20] Skodras G, Kaldis SP, Sofialidis D, Faltsi O, Grammelis P, Sakellaropoulos GP. Particulate removal via electrostatic precipitators CFD simulation. Fuel Process Technol 2006; 87(7): 623-631.

[21] Papadikis K, Gu S, Bridgwater AV. Eulerian Model for the Condensation of Pyrolysis Vapors in a Water Condenser. Energ Fuel 2011; 25: 1859-1868.

[22] Kiran Kumar Palla VS, Papadikis K, Gu S. Computational modelling of the condensation of fast pyrolysis vapours in a quenching column. Part A: Hydrodynamics, heat transfer and design optimisation. Fuel Process Technol 2015; 131: 59-68.

[23] Mohan D, Pittman CU, Steele PH. Pyrolysis of wood/biomass for bio-oil: a critical review. Energ Fuel 2006; 20: 848-89.

[24] Tamim J, Hallett WLH. A continuous thermodynamics model for multicomponent droplet vaporization. Chem Eng Sci 1995; 18: 2933-42.

[25] Zhang L, Kong S-C. High-pressure vaporization modeling of multi-component petroleum-biofuel mixtures under engine conditions. Combust Flame 2011; 50: 17051717. 
[26] Zhang L, Kong S-C. Multicomponent vaporization modeling of bio-oil and its mixtures with other fuels. Fuel 2012; 95: 471-480.

[27] Hallett WLH, Clark NA. A model for the evaporation of biomass pyrolysis oil droplets. Fuel 2006; 85(4): 532-544.

[28] Hallett WLH, Legault NV. Modelling biodiesel droplet evaporation using continuous thermodynamics. Fuel 2011; 90(3): 1221-1228.

[29] Oasmaa A, Kuoppala E, Elliott DC. Development of the Basis for an Analytical Protocol for Feeds and Products of Bio-oil Hydrotreatment. Energ Fuel 2012; 26: 24542460 .

[30] Butler E, Devlin G, Meier D, McDonnelle K. Characterisation of spruce, salix, miscanthus and wheat straw for pyrolysis applications. Bioresource Technol 2013; 131: 202-209.

[31] Brett J, Ooi A, Soria J. The effect of internal diffusion on an evaporating bio-oil droplet - The chemistry free case. Biomass Bioenerg 2010; 34(8): 1134-1140.

[32] Salter E. H.; Catalytic pyrolysis of biomass for improved liquid fuel quality. Ph.D. Thesis, Bio-energy Research Group, Aston University, 2001.

[33] Amutio M, Lopez G, Aguado R, Artetxe M, Bilbao J. Influence of temperature on biomass pyrolysis in a conical spouted bed reactor. Resour Conserv Recycling 2012; 59: 23-31.

[34] Poling BE, Prauznitz JM, O'Connell JP. The properties of gases and liquids. Fifth edition, McGraw-Hill, 2001.

[35] Marrero-Morejon J, Pardillo-Fontdevila E. Estimation of pure compound properties using group-interaction contributions, AIChE J 1999; 45(3): 615-621.

[36] Mejbri Kh, Bellagi A. Corresponding states correlation for the saturated vapor pressure of pure fluids. Thermochim Acta 2005; 436(1-2): 140-149.

[37] Dean DE, Stiel LI. The viscosity of non-polar gas mixtures at moderate and high pressures. AIChE J. 1965; 11(3): 526-532.

[38] Chung T-H, Ajlan M, Lee LL, Starling KE. Generalized multiparameter correlation for nonpolar and polar fluid transport properties. Ind Eng Chem Res 1988; 27(4): 671679.

[39] Reid RC, Prauznitz JM, Sherwood TK. The properties of gases and liquids. McGrawHill, 1977.

[40] Stull DR, Westrum Jr. EF, Sinke GC. The chemical thermodynamics of organic compounds. John Wiley \& Sons, Inc., 1969. 
[41] Pitzer KS, Lippmann DZ, Curl RF Jr, Huggins CM, Petersen DE. The Volumetric and Thermodynamic Properties of Fluids. II. Compressibility Factor, Vapor Pressure and Entropy of Vaporization. J Am Chem Soc 1955; 77(13): 3433-3440.

[42] Oasmaa A, Peacocke C. A guide to physical property characterisation of biomassderived fast pyrolysis liquids. VTT Publications, VTT technical research centre of Finland, ESPOO, 2001.

[43] Oasmaa A, Peacocke C, Gust S, Meier D, McLellan R. Norms and Standards for Pyrolysis Liquids. End-User Requirements and Specifications, Energ Fuel 2005; 19(5): $2155-2163$.

[44] L. Schiller; A.Z. Naumann; Ver Deut Ing 1933; 77: 318.

[45] Ranz W, Marshall W. Evaporation from drops, Part II, Chem Eng Prog 1952; 48: 173-180.

[46] Fivga A. Comparison of the effect of pre-treatment and catalysts on liquid quality from fast pyrolysis of biomass. Ph.D. Thesis, Bio-energy Research Group, Aston University, 2011. 


\section{List of figures:}

588 1. Double surface water cooled condenser

2. Bio-oil mass fraction contours.

590

3. Vapour temperature contour and average temperature plot.

4. Relative saturation plot.

5. Mass fractions of the pyrolysis vapour components at inlet.

6. Relative mass fraction of the vapour components.

7. Maximum velocity plot.

8. Average vapour pressure plot.

9. Cumulative mass source plot.

10. Mass source of the condensed vapour components.

11. Reduced temperature of vapour components.

599

12. Enthalpy source due to the condensation.

600

13. Velocity of the pyrolysis vapour 
List of Tables:

Table 1: Chemical compounds in the pyrolysis vapours and their properties

\begin{tabular}{|l|l|l|l|l|l|l|l|}
\hline $\begin{array}{l}\text { Chemical } \\
\text { compound }\end{array}$ & $\begin{array}{l}\text { Initial } \\
\text { Volume } \\
\text { fraction }\end{array}$ & $\begin{array}{l}\text { Molecular } \\
\text { weight } \\
(\mathrm{g} / \mathrm{mol})\end{array}$ & $\begin{array}{l}\text { Critical } \\
\text { Temperature } \\
(\mathrm{K})\end{array}$ & $\begin{array}{l}\text { Critical } \\
\text { pressure } \\
(\mathrm{atm})\end{array}$ & $\begin{array}{l}\text { Critical } \\
\text { volume } \\
\left(\mathrm{cm}^{3} / \mathrm{mol}\right)\end{array}$ & $\begin{array}{l}\text { Acentric } \\
\text { factor }\end{array}$ & $\begin{array}{l}\text { Critical } \\
\text { compressibility } \\
\text { factor }\end{array}$ \\
\hline Acetic acid & 0.037 & 60.05 & 594 & 57.1 & 171 & 0.454 & 0.2 \\
Butanal & 0.109 & 72.11 & 524 & 40 & 278 & 0.352 & 0.26 \\
Butyric acid & 0.011 & 88.11 & 628 & 52 & 292 & 0.67 & 0.295 \\
Coniferyl alcohol & 0.19 & 180.2 & 569.9 & 33.6 & 482 & 1.155 & 0.346 \\
Formic acid & 0.042 & 46.02 & 580 & 57.34 & 120 & 0.368 & 0.1445 \\
Guaiacol & 0.108 & 124.14 & 696.8 & 46.613 & 338 & 0.563 & 0.275 \\
Pentanal & 0.021 & 86.13 & 554 & 35 & 229 & 0.44 & 0.26 \\
Phenol & 0.054 & 94.11 & 694.2 & 60.5 & 223 & 0.313 & 0.24 \\
Propanal & 0.144 & 58.08 & 496 & 47 & 230 & 0.536 & 0.26 \\
Propionic acid & 0.017 & 74.08 & 612 & 53 & 56 & 0.344 & 0.242 \\
Water Vapour & 0.267 & 18.01 & 647.3 & 217.6 & & 0.229 \\
\hline
\end{tabular}

*The initial volume fraction excludes the carrier gas Nitrogen. 
Table 2: Coefficients of eqs. 2 and 3.

\begin{tabular}{|c|c|}
\hline$k$ & $\gamma_{k}$ \\
\hline 1 & -5.53357241 \\
2 & 11.0210515 \\
3 & -0.51243147 \\
4 & -10.6722729 \\
5 & 29.4364927 \\
6 & -0.44101891 \\
\hline
\end{tabular}


Table 3: Heat capacities of individual components present in the vapour

\begin{tabular}{|l|l|l|l|}
\hline & \multicolumn{3}{|c|}{$\mathrm{C}_{\mathrm{P}}=\mathrm{A}_{1}+\mathrm{A}_{2} T+\mathrm{A}_{3} T^{2}$} \\
\hline Chemical compound & $\mathrm{A}_{1}$ & $\mathrm{~A}_{2}$ & \multicolumn{1}{|c|}{$\mathrm{A}_{3}$} \\
\hline Acetic acid & 195.74849 & 3.5237048 & -0.001545339 \\
Butanal & 245.97362 & 4.4604585 & -0.001734686 \\
Butyric acid & 229.03995 & 3.9854485 & -0.001549761 \\
Coniferyl alcohol & 527.97236 & 3.1066709 & -0.000768719 \\
Formic acid & 326.7 & 2.5160000 & -0.00105 \\
Guaiacol & 531.24523 & 3.0758568 & -0.000739824 \\
Pentanal & 202.39221 & 4.7575163 & -0.001883003 \\
Phenol & -158.75528 & 4.9638417 & -0.002442437 \\
Propanal & 240.36658 & 4.2292475 & -0.001671269 \\
Propionic acid & 164.9201 & 4.0156030 & -0.001735477 \\
Water Vapour & 1779.0173 & 0.1717701 & 0.000362651 \\
\hline
\end{tabular}


Table 4: Bio-oil properties

\begin{tabular}{|l|r|}
\hline Property & Value \\
\hline Density $(\mathrm{kg} / \mathrm{m} 3)$ & 1200 \\
Thermal conductivity $(\mathrm{W} / \mathrm{m} \mathrm{K})$ & 0.386 \\
Specific heat capacity $(\mathrm{J} / \mathrm{kg} \mathrm{K})$ & 3200 \\
Viscosity $(\mathrm{Pa} \mathrm{s})^{*}$ & $12.9881-0.080204 T+0.000124 T^{2}$ \\
\hline
\end{tabular}

* Temperature unit is $\mathrm{K}$. 


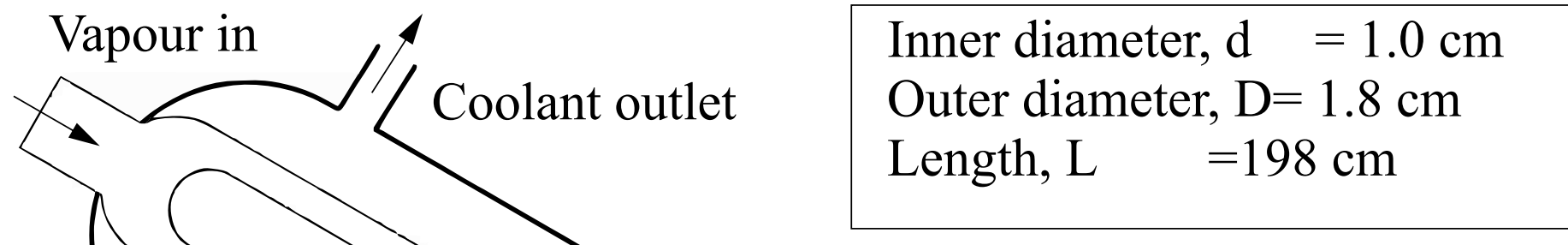

Inner cooling surface

Outer cooling surface

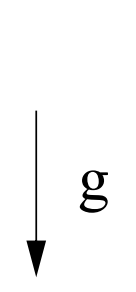

Coolant Inlet

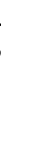

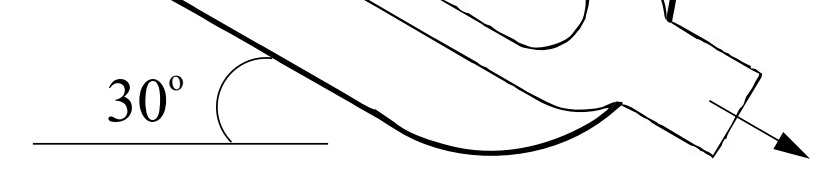

Vapour out 
figure03.pqf 00

o

500

总 400

芩 300

0

焉 200

志 100

0
0
0.05
0.10
0.15
0.20
Axial distance from inlet (m) 
figure04.pdf
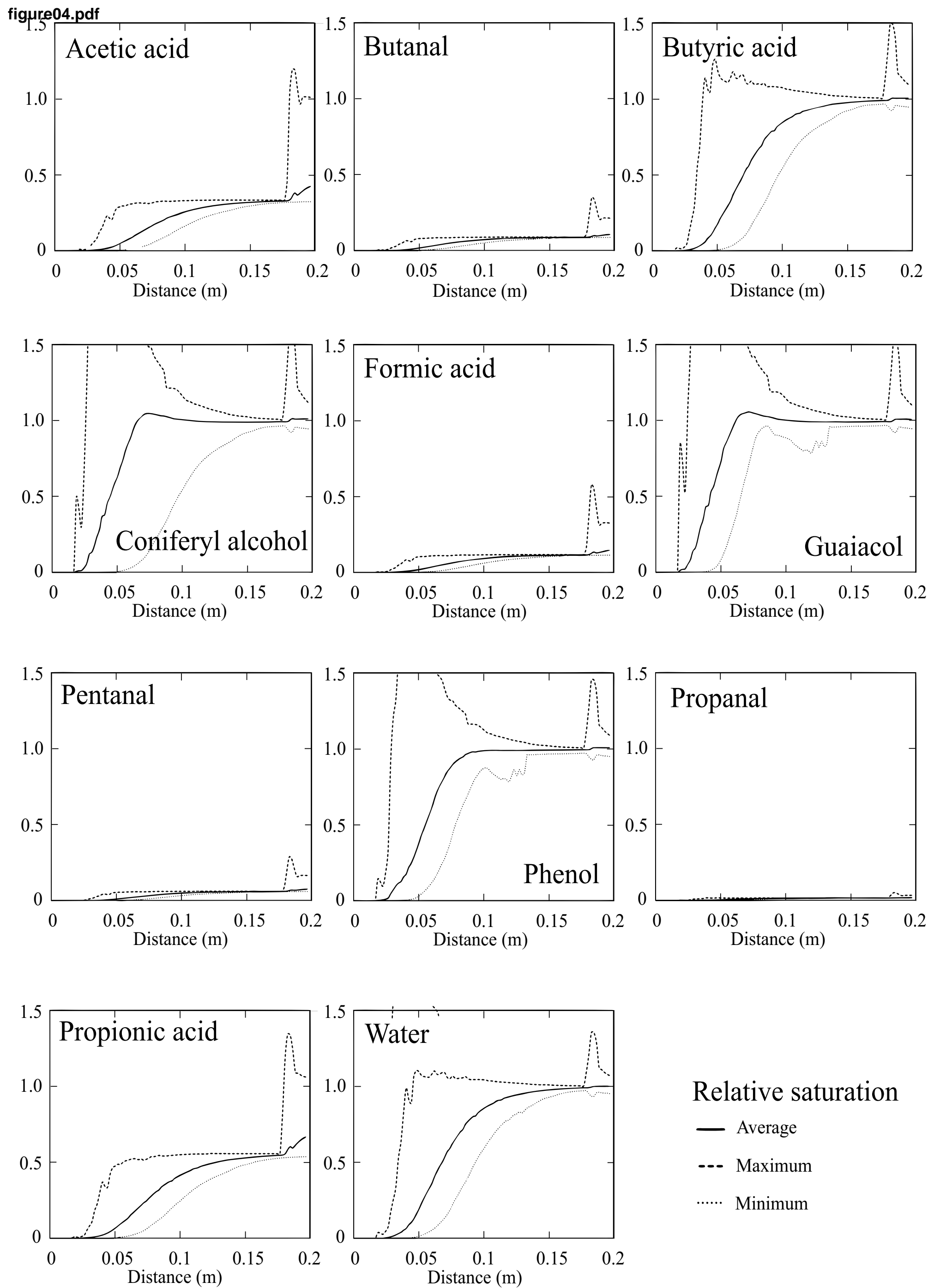

Relative saturation

- Average

-.- Maximum

Minimum 
figure05.pdf

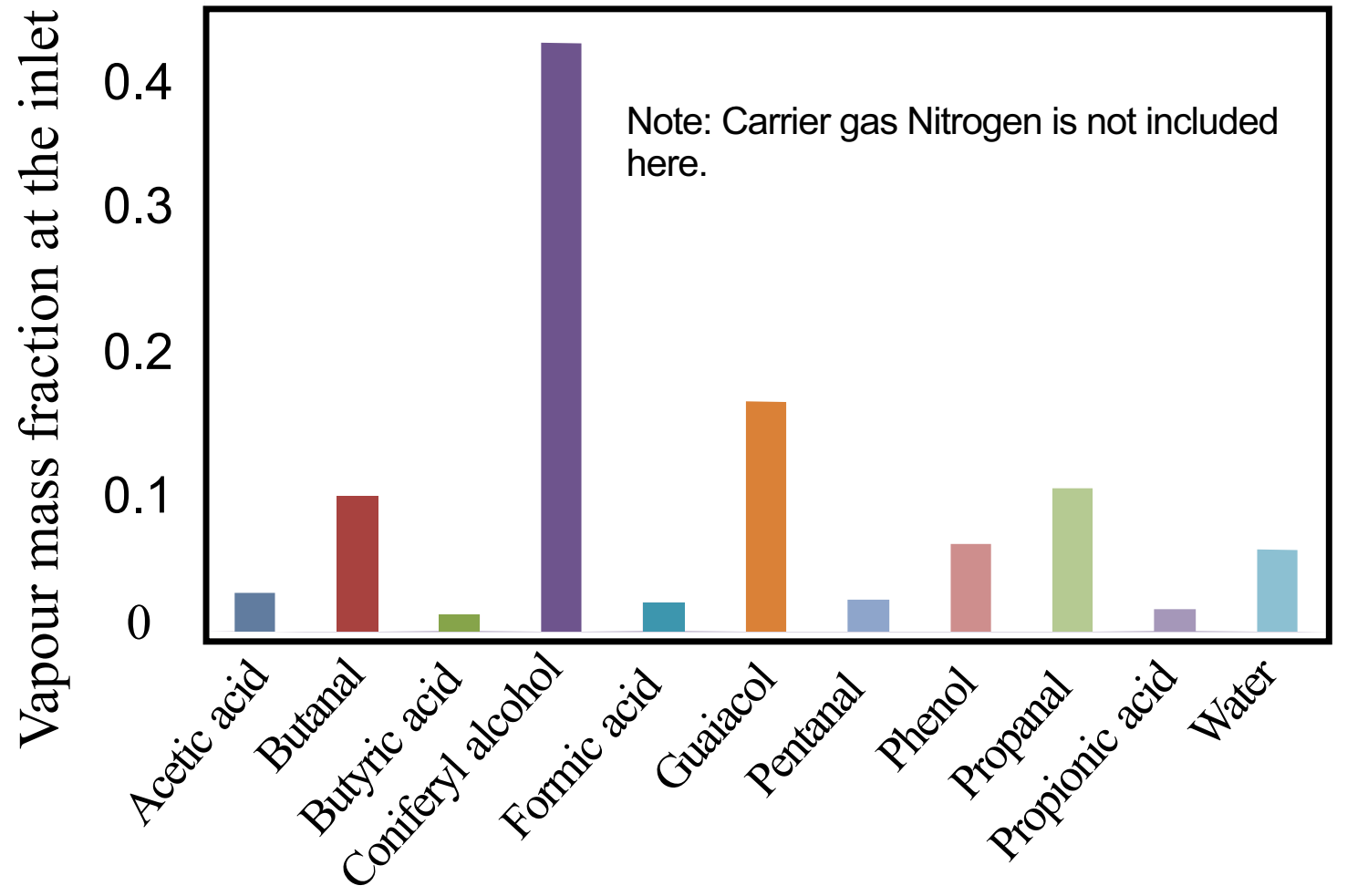


Relative mass fraction compared to the inlet mass fractions.

1.16
1.10
1.04
0.99
0.93
0.87
0.81
0.75
0.70
0.64
0.58
0.52
0.46
0.41
0.35
0.29
0.23
0.17
0.12
0.06
0.00

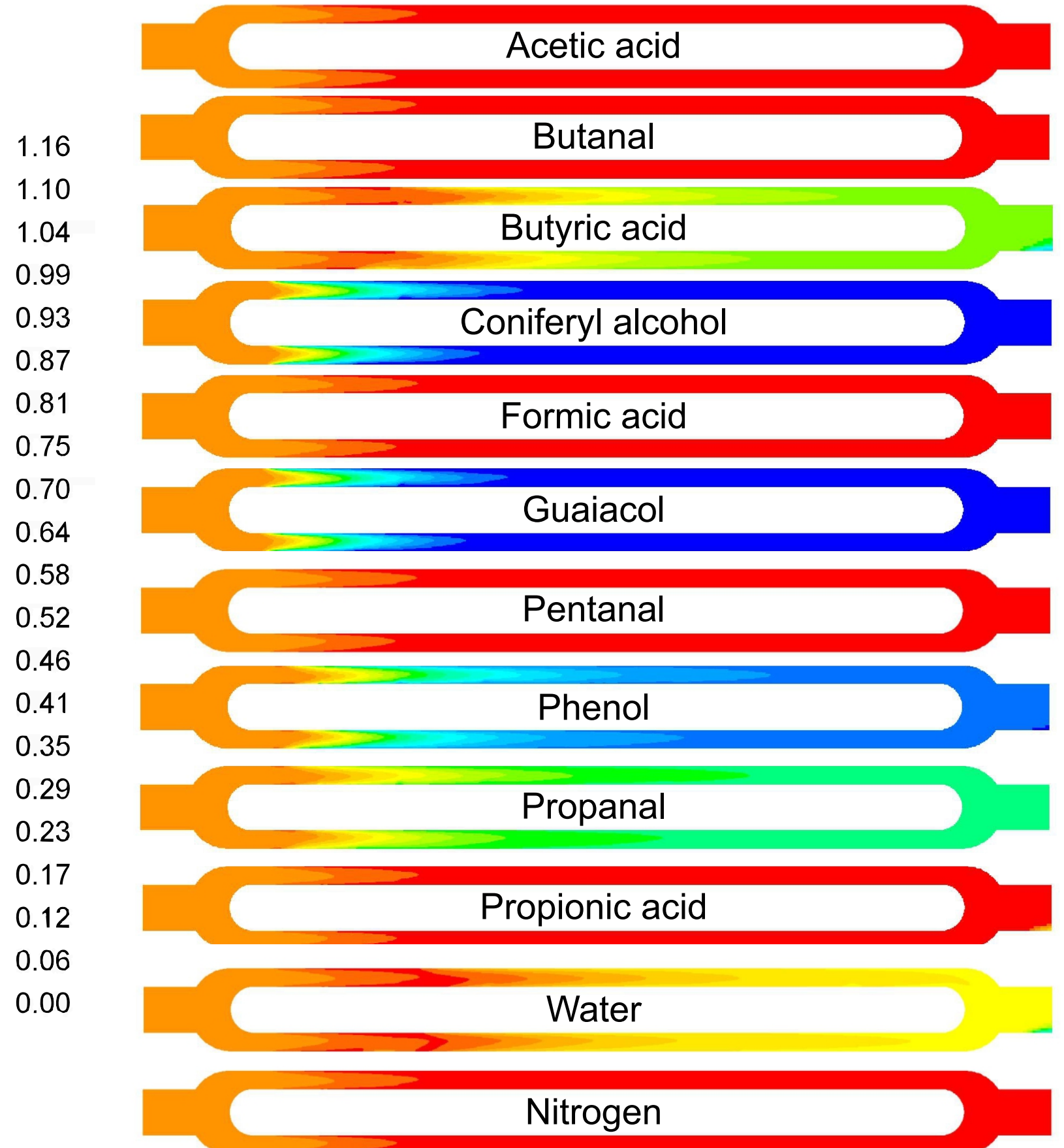

\section{Coniferyl alcohol}

Formic acid

Guaiacol

Pentanal

Phenol

Propanal

Propionic acid

Water

Nitrogen 


\section{figure07.pdf}

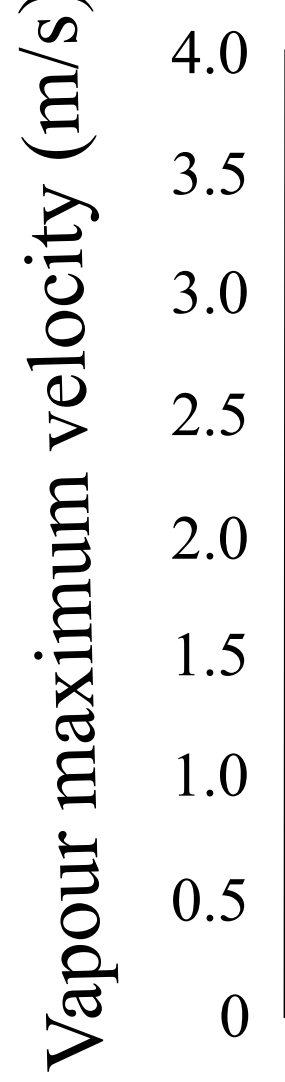

0

0.05

0.10

0.15

0.20

Axial distance from inlet (m) 
figure08.pdf 5.0

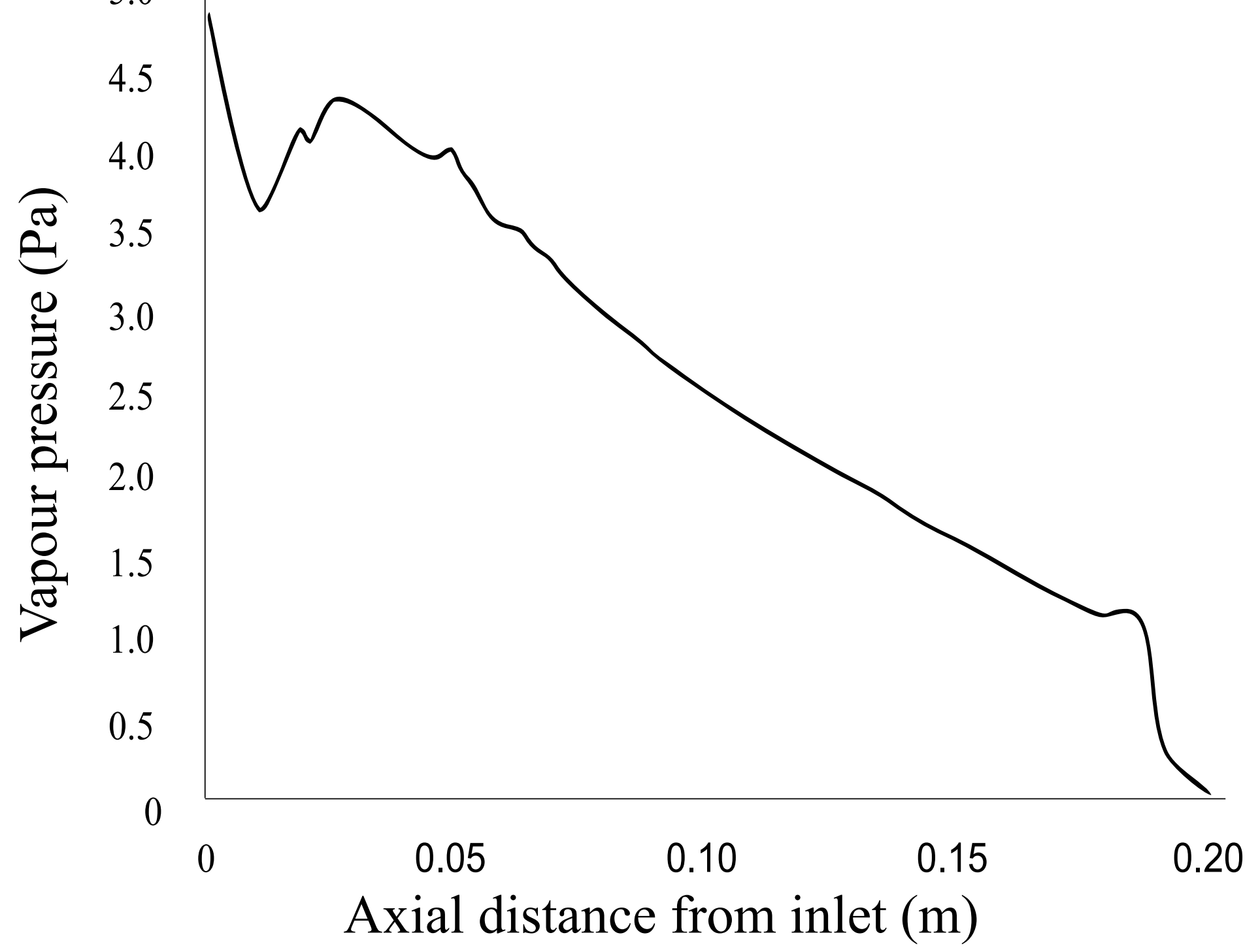




\section{....... Guaiacol \\ - - Phenol \\ - Water}

-. - Butyric acid

Propionic acid

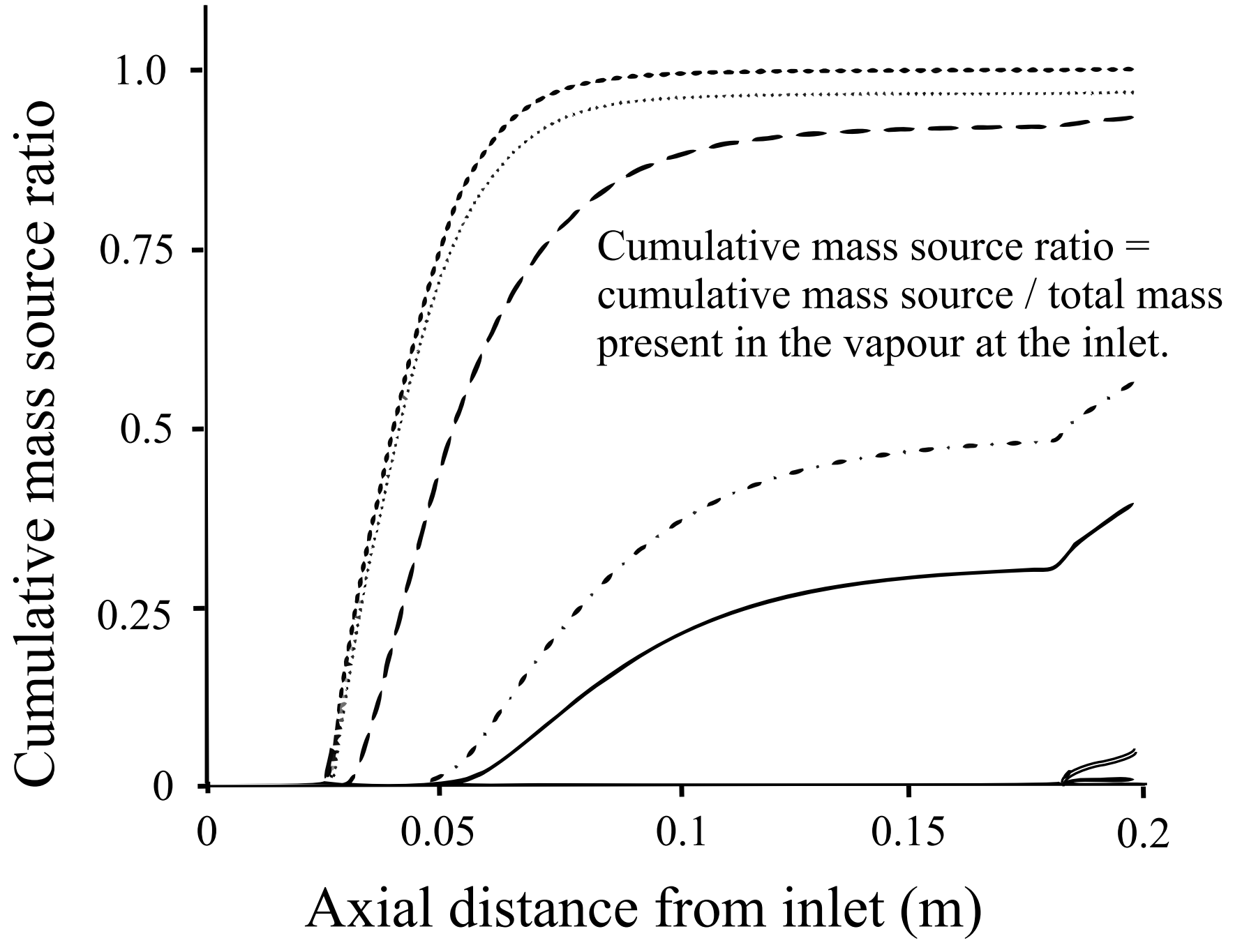


....... Guaiacol

- - Phenol

Water
Coniferyl alcohol

-. - Butyric acid

$=$ Propionic acid

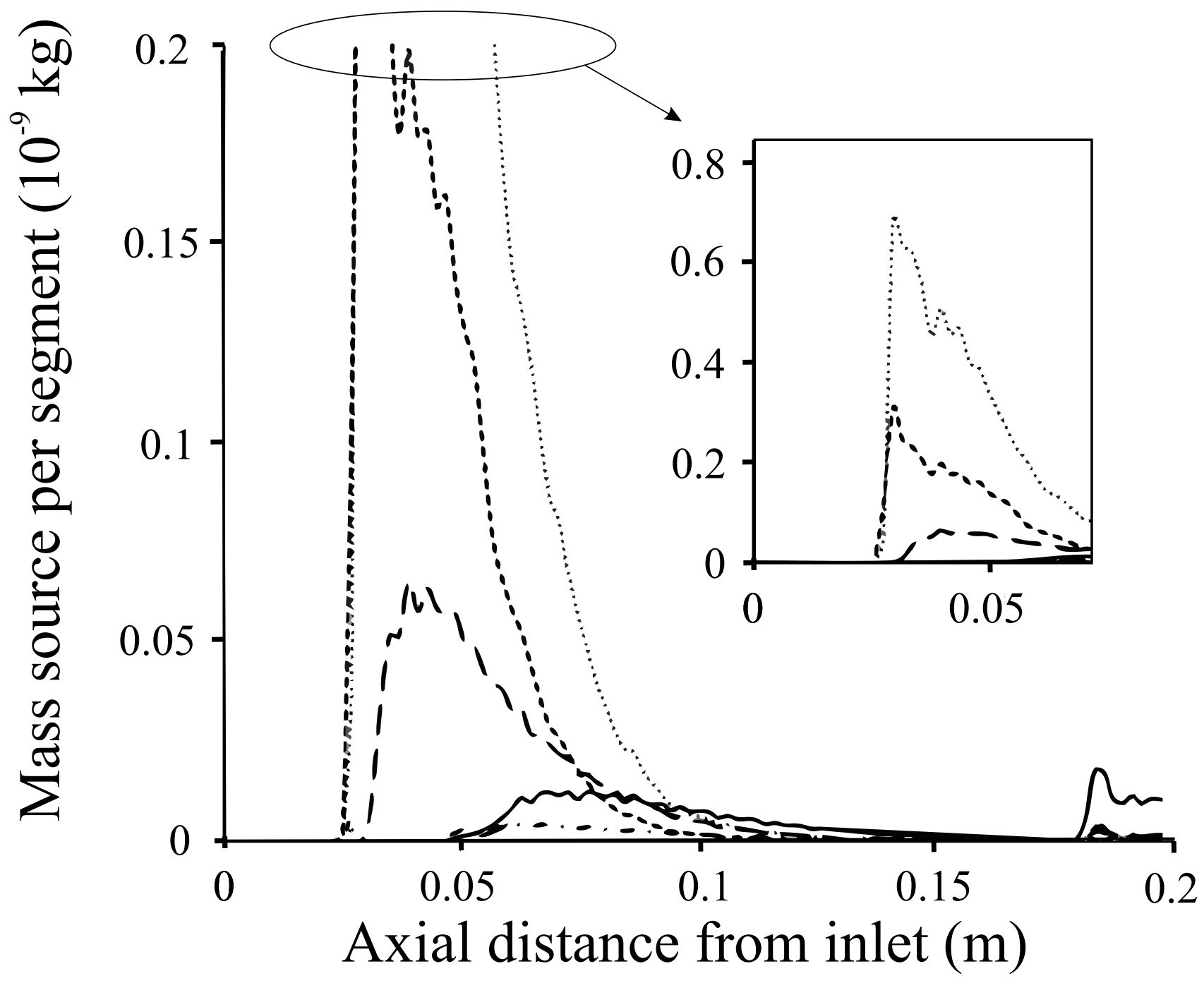


figure11.pdf

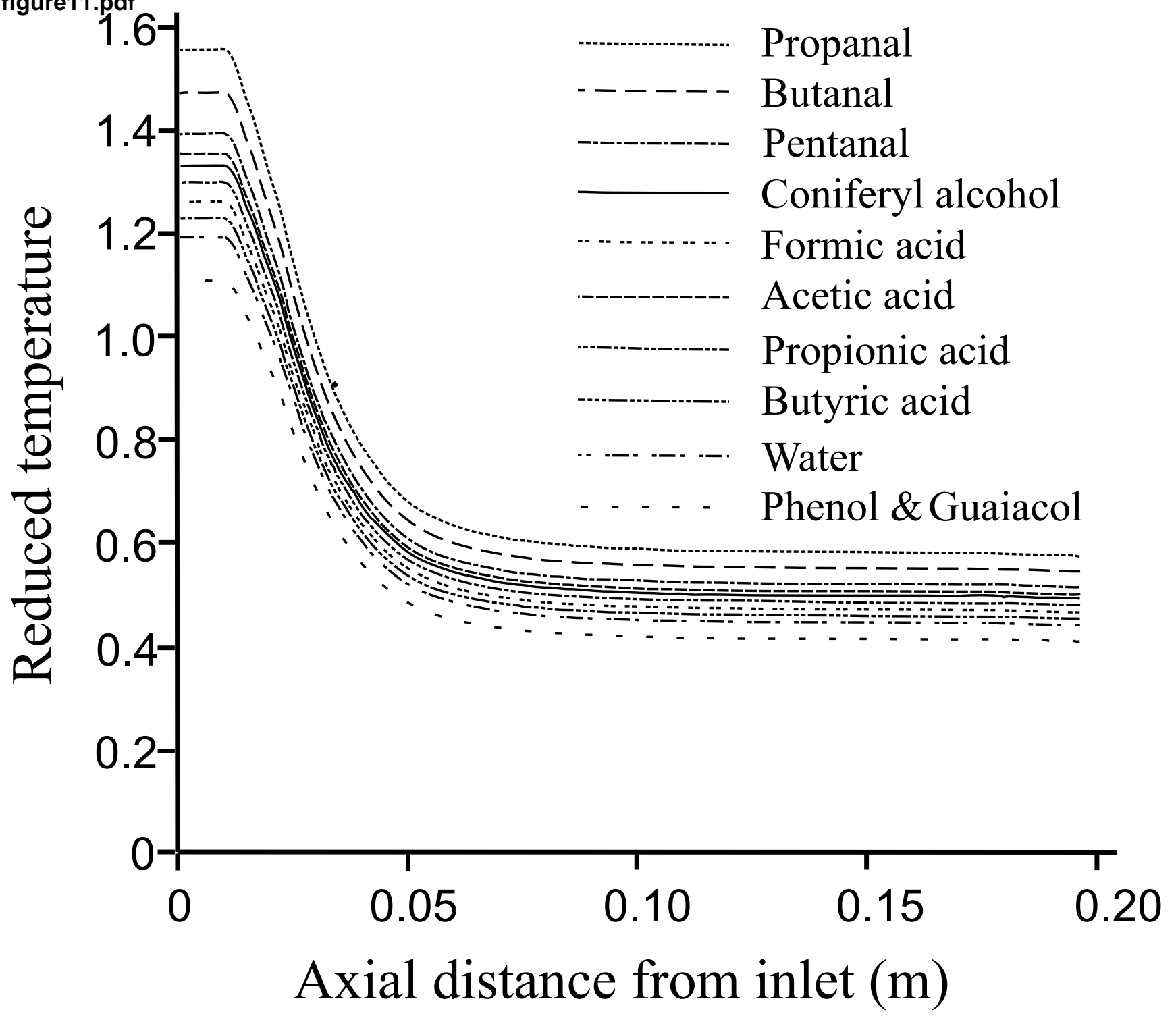




\section{figure13.pdf

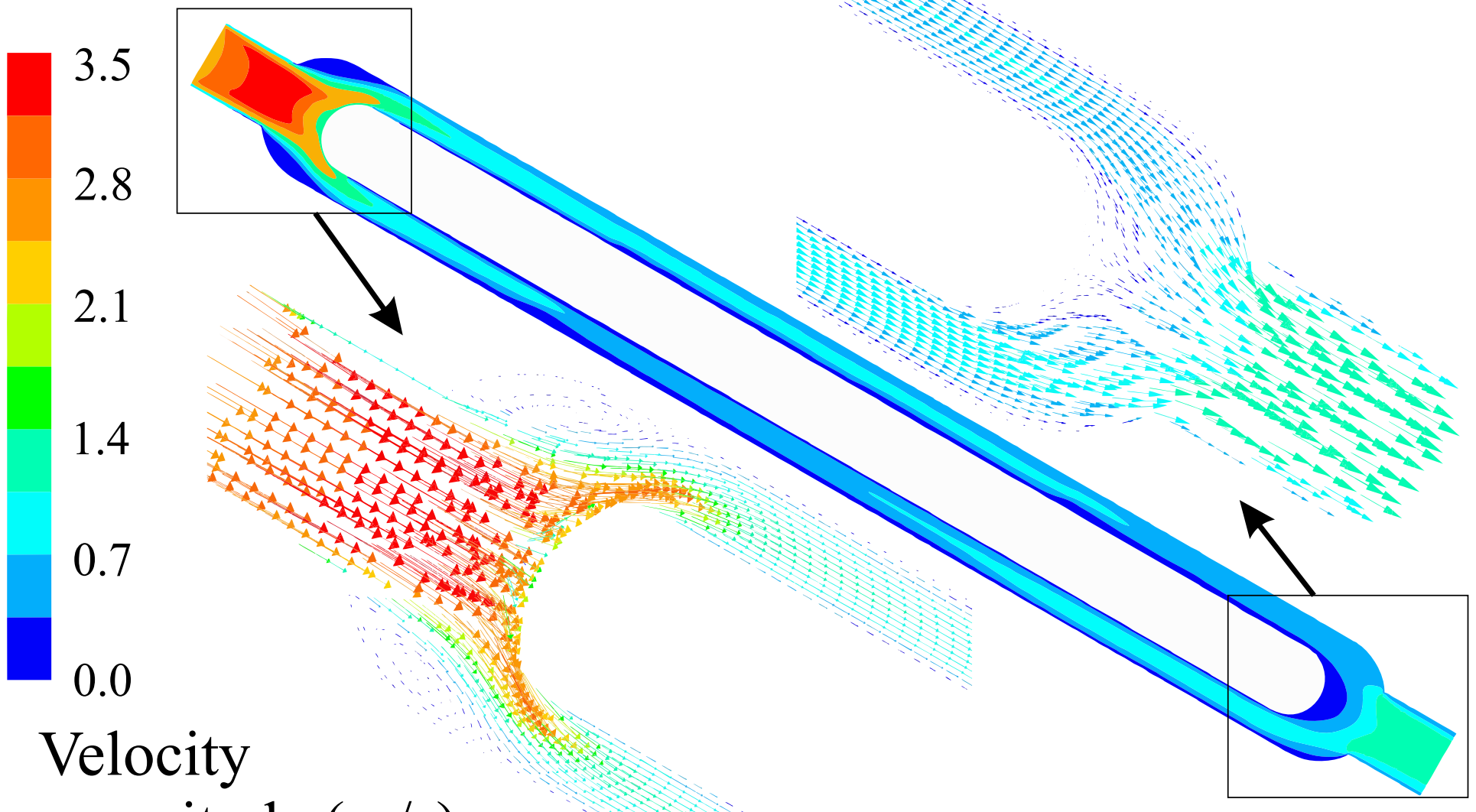
magnitude $(\mathrm{m} / \mathrm{s})$

2.8

2.1

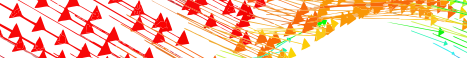

)

